$\xi=$

\title{
Isolation, characterization and decolorization of textile dyes by fungal isolates from textile effluents
}

\author{
Femi-Ola Titilayo Olufunke*, Adeyemi Emmanuel, Atere Ayowole Victor \\ Department of Microbiology, Ekiti State University \\ *Corresponding author E-mail: titifemi2006@yahoo.com
}

\begin{abstract}
Synthetic dyes have an adverse effect on the aquatic ecosystem and their toxic component has to be removed from the effluent before their exoneration. Microorganisms have the potentials to degrade complex and recalcitrant organic compounds into simpler fragments achieving complete mineralization. Thus, the aim of this work is to isolate and investigate the degradative potential of fungal isolates recovered from textile effluents. The fungal isolates encountered includes; Aspergillus niger (14.3\%), Aspergillus fumigatus (14.3\%), Cryptococcus sp. $(28.6 \%)$ and Candida albican (42.9\%). The fungal isolates utilized some selected synthetic dyes (Malachite green, Methylene blue, Eosin Y and Carbol fuchsine) as sole source of carbon and nitrogen. All the fungal isolates exhibited degradative and decolourization potential against the different dyes tested at varying degree. Highest decolourization (79.4\%) was obtained by Aspergillus niger for Eosin Y dye, followed by Cryptococcus sp. (77.0\%) for the same dye after five days incubation. However the least decolourization efficiency $(35 \%)$ was obtained by Aspergillus fumigatus for Malachite green. The results have demonstrated the potential of the fungal isolates for the treatment of dye wastewater.
\end{abstract}

Keywords: Decolourization; Dye; Fungal Isolates.

\section{Introduction}

Growing environmental pollution resulting from rapid industrial development is one of the challenges facing the modern world. The textile industry releases about 10 to $15 \%$ of the dye, which find its way into waste water. It chiefly consists of residue dyes, surfactants, salts, and chlorinated compound (Selvam et al., 2003). Thus, the colour removal of textile waste water is a major environmental concern. Therefore, industrial effluents like textile waste water containing dyes must be treated before their discharge into the environment. The dye waste water from the textile is one of the most difficult waste water to treat, because of their commercial importance. The impact and toxicity of dyes have been extensively studied. Color can be removed from waste water by chemical and physical method including absorption, coagulationflocculation, oxidation and electrochemical methods (Thakur et al., 2012). Chemical and physical method used may also include ion-exchange, irradiation, precipitation, ozonation, and oxidation via chlorine, electro floatation, detrolysis, and petroxide (Nosheen et al., 2000). These methods are quite expensive, have operational problems and generate huge quantities of sludge. Among low cost, viable alternatives for effluent treatment and decolourization, the biological systems are recognized by their capacity to reduce biochemical oxygen demand (BOD) and chemical oxygen demand (COD) by convectional aerobic degradation.

The treatment based on using microbes capable of degrading or decolourizing these recalcitrant compounds is environmental friendly and can lead to mineralization of the target compounds. The effectiveness of these treatment systems depends upon the survival and adaptability of the microorganisms during the treatment processes (Thakur et al., 2012).
Biological processes convert organic compounds completely into water and carbon dioxide; it has low cost and is very easy to use (Ali et al., 2009) but due to the detrimental effect of reactive dyes on the microbial population, efficiency of the process is reduced (Ogawa et al., 1982). Some bacterial such as Micrococcus luteus, Staphylococcus aureus, Bacillus spp (Mahbub et al., 2001), Proteus mirabilis (Joshi et al., 2008), Pseudomonas spp. (Zimmermann et al., 1982), and Aeromonas spp. (Chen et al., 2008) has already been reported of having the capability decolorizing textile dye. Therefore, it is imperative to research into the organisms associated with effluent from textile and their ability to degrade dyes.

\section{Materials and methods}

\subsection{Collection of sample}

The textile effluents (namely yellow and blue dyes) used in this research was collected the textile industries situated at Osogbo, Osun State, Nigeria. The samples were collected in sterile plastic container and transported to the laboratory for bacteriological analysis.

\subsection{Bacteriological analysis}

The standard pour plate method was used in the isolation process from the dye using nutrient agar. Isolates were characterized based on their cultural and biochemical characteristics. The following biochemical analyses were carried out: oxidase, catalase, coagulase test, urease test, motility, sucrose, mannitol, glucose, and citrate utilization (Jason, 2004). The tests were used to identify the 
isolates according to Bergey's manual of determinative bacteriology (Holt et al., 1994).

\subsection{Mycological analysis}

The Potato Dextrose Agar (PDA) was used in the isolation of fungi present in the effluent, a standard pour plate method was adopted, and inoculated PDA plates were incubated at room temperature for 5 days. Further test were carried out to determine the sugar fermentation ability of each isolates in order to characterise the isolates. The sugar fermentation tests were carried out based on their ability to utilize lactose, maltose, sucrose and their ability to produce urea enzyme (urease) (Mobely et al., 1995). The identification was done by comparing the experimental results with the description in manual of imperfect fungi (Barnet and Hunter, 1972).

\subsection{Decolorization and degradation studies of the fungi isolates}

\subsubsection{Media}

Dye decolourization was determined qualitatively using Saboraud Dextrose Agar (SDA) and Potato Dextrose Agar (PDA). Fungal inoculums were prepared in Potato Dextrose Broth. Czapek-Dox Broth $\left(\mathrm{g} \mathrm{l}^{-1}\right.$ sucrose $30 \mathrm{~g}$, sodium nitrate $2 \mathrm{~g}$, potassium hydrogen phosphate $1 \mathrm{~g}$, magnesium sulphate $0.5 \mathrm{~g}$, potassium chloride $0.5 \mathrm{~g}$, iron (ii) sulphate $0.01 \mathrm{~g}$ and distilled water $1000 \mathrm{ml}$ ): serves as the complex medium to conserve the inoculums and enhance the proper optimization of the conditions required for the dye decolorization.

\subsubsection{Degradation studies on solid media}

Fungal isolates were inoculated onto SDA plate containing the dye samples for the demonstration of dye degradation on solid media. The degradation was observed by measuring the clearance zone around the fungi colonies after being incubated for 12 days at 25 ${ }^{\circ} \mathrm{C}$.

\subsubsection{Decolourization analyses}

Fifty millilitres of Czapek-Dox Broth (pH 5.5) contained in $250 \mathrm{ml}$ conical flask was sterilized by autoclaving at $121^{\circ} \mathrm{C}$ at $15 \mathrm{psi}$ for 15 minutes in an autoclave. The inoculums of $2 \mathrm{ml}$ (fungal mycelia) were taken from pre-cultured Potato Dextrose broth media and introduce into the complex salt media for the decolorization study. The fungal inoculums were incubated for 5 days, on the fifth day, samples of dye were added $(3 \mathrm{ml}$ each $0.05 \% \mathrm{v} / \mathrm{v})$ to the culture media and were kept at $30^{\circ} \mathrm{C}$ and were manually stirred at every 6 hrs for 6 days to achieve uniform distribution of dyes and inoculums. Control media were also prepared without inoculums added (Jothimani and Prabakaran, 2003). Laboratory dyes used includes malachite green, carbon fuchsine, methylene blue and eosin Y. Five millimetres of content were mixed well and filtered through Whatman no 1 filter paper and absorbance were measured for tests and controls of all samples at $590 \mathrm{~nm}$ to estimate the decolorization percentage using the formula:

$$
\left.\mathrm{D}=\underline{\left(\mathrm{A}_{0}\right.} \underline{\underline{\mathrm{A}_{0}}} \mathrm{~A}_{1}\right) \times 100
$$

$\mathrm{D}=$ Decolorization rate

$\mathrm{A}_{0}=$ Initial absorbance or absorbance of control

$\mathrm{A}_{1}=$ final absorbance or the absorbance of the samples test (Moorthi et al, 2007).

\section{Results}

The total viable bacteria found in the dye sample $\mathrm{Y}$ and $\mathrm{X}$ were $5.0 \times 10^{6}$ and $7.0 \times 10^{7} \mathrm{CFU} \mathrm{ml}{ }^{-1}$ respectively and the total viable fungi cells in the two dyes samples were both $7 \times 10^{7}$ cell propa- gules $\mathrm{ml}^{-1}$. The bacteria isolated from the two effluents were Pseudomonas aeruginosa, Staphylococcus aureus, Streptococcus faecalis, Escherichia coli and Bacillus subtilis.

Table 1: Physiochemical Characteristics of Effluent Samples and the Total

\begin{tabular}{|c|c|c|c|}
\hline $\begin{array}{l}\text { Effluent } \\
\text { samples }\end{array}$ & Color & 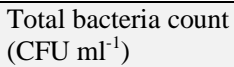 & $\begin{array}{l}\text { Total fungal count } \\
\left(\mathrm{ml}^{-1}\right)\end{array}$ \\
\hline$X$ & $\begin{array}{l}\text { Yel- } \\
\text { low }\end{array}$ & $7.0 \times 10^{7}$ & $7.0 \times 10^{7}$ \\
\hline Y & Blue & $5.0 \times 10^{6}$ & $7.0 \times 10^{7}$ \\
\hline
\end{tabular}
Viable Count of Microbes Present

The fungal isolates encountered include Candida albican, Aspergillus niger, Aspergillus fumigatus and Cryptococcus spp. with occurrence rate of $42.9 \%, 14.3 \%, 28.6 \%$ and $14.3 \%$ respectively (Table 2).

Table 2: Rate of Occurrence of Fungal Isolates in Dye Samples

\begin{tabular}{lll}
\hline Organism & No of occurrence & Occurrence rate $(\%)$ \\
\hline Aspergillus niger & 2 & $14.3 \pm 0.1$ \\
Aspergillus fumigatus & 2 & $14.3 \pm 0.1$ \\
Cryptococcus spp. & 4 & $28.6 \pm 0.1$ \\
Candida albican & 6 & $42.9 \pm 0.1$ \\
\hline
\end{tabular}

Aspergillus niger shows considerable degradation ability on all dyes by at least $47 \mathrm{~mm}$ (26\%), Aspergillus niger was able to decolorize methylene blue more than any of the fungi isolates. There were significant decolorization of malachite green by Cryptococcus spp., it was able to decolorize eventually all dyes on the medium and this specie shows considerable decolorization ability on other dye samples. Malachite green and metyhlene blue were recalcitrant to Aspergillus fumigatus and Candida albican respectively and both show low decolorization ability on carbon fuchsine by creating zone of clearance of $5 \mathrm{~mm}$ and $20 \mathrm{~mm}$ in diameter respectively (figure 1).

The ability of the four different fungal isolates to decolorize dyes in liquid was determined using Czapek Dox broth. The four isolated fungal strains (C. albican, A. niger, A. fumigatus and Cryptococcus spp.) were used to study decolorization of the selected laboratory dyes namely; methylene blue, malachite green, carbon fuchsine and eosin $\mathrm{Y}$ which were added on the $5^{\text {th }}$ day of prior incubation in Czapek Dox broth. The decolorization efficiencies were measured on the $6^{\text {th }}$ day of incubation. The result revealed that all the isolated fungal species had variable potential to decolorize different textile dyes (Figure 2, 3, 4, 5). The most potent fungal strains in decolorizing methylene blue was A. niger followed by Cryptococcus spp. and the most recalcitrant among all the dye studies for degradation by the isolated fungi was malachite green in which the total \% decolorization by the four fungal isolates was $48 \%$. The degradation efficiencies by the fungi strains varied from 48 to $66 \%$. 


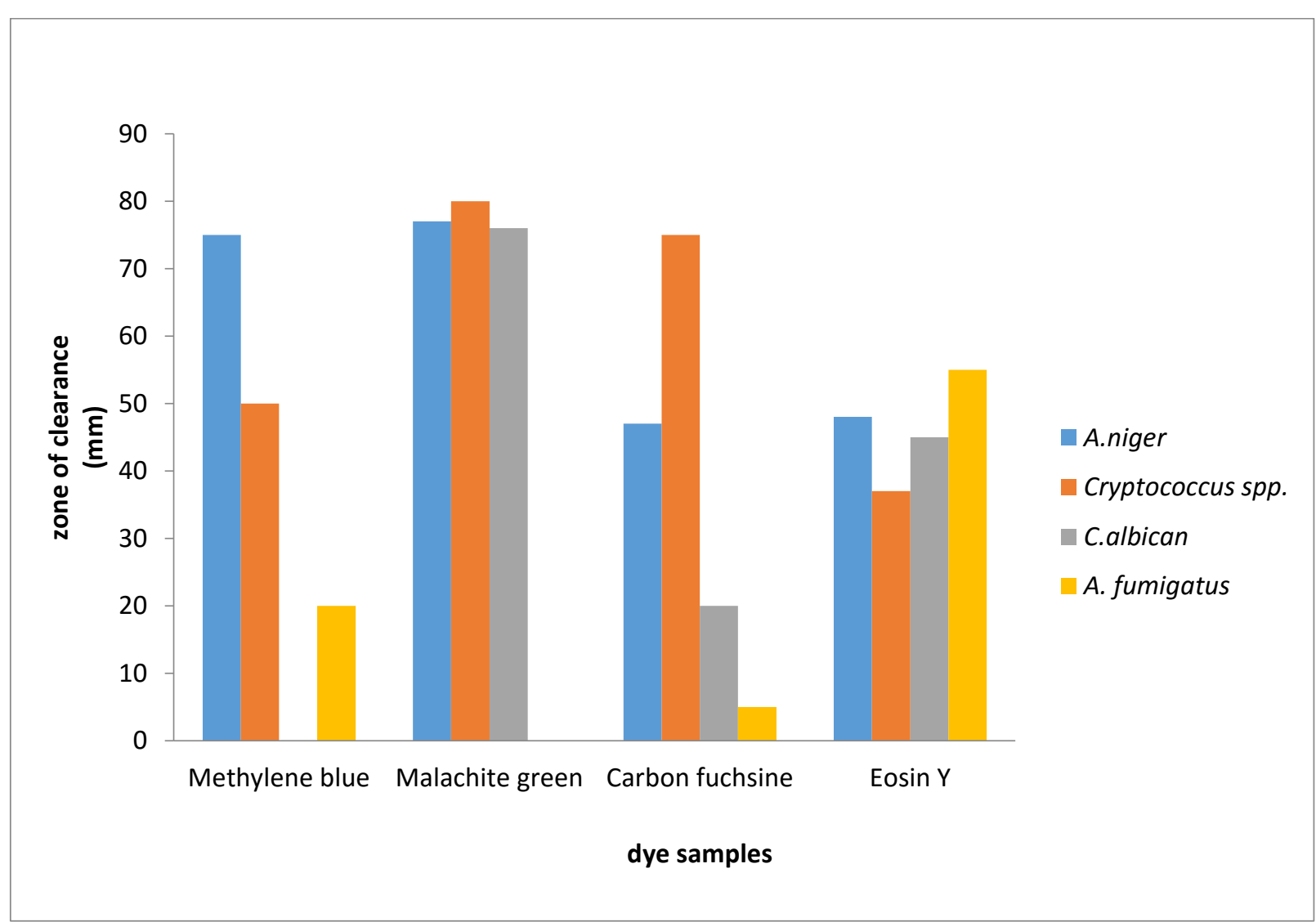

Fig. 1: Decolourization of Dyes by Fungal Isolates on Solid Media.

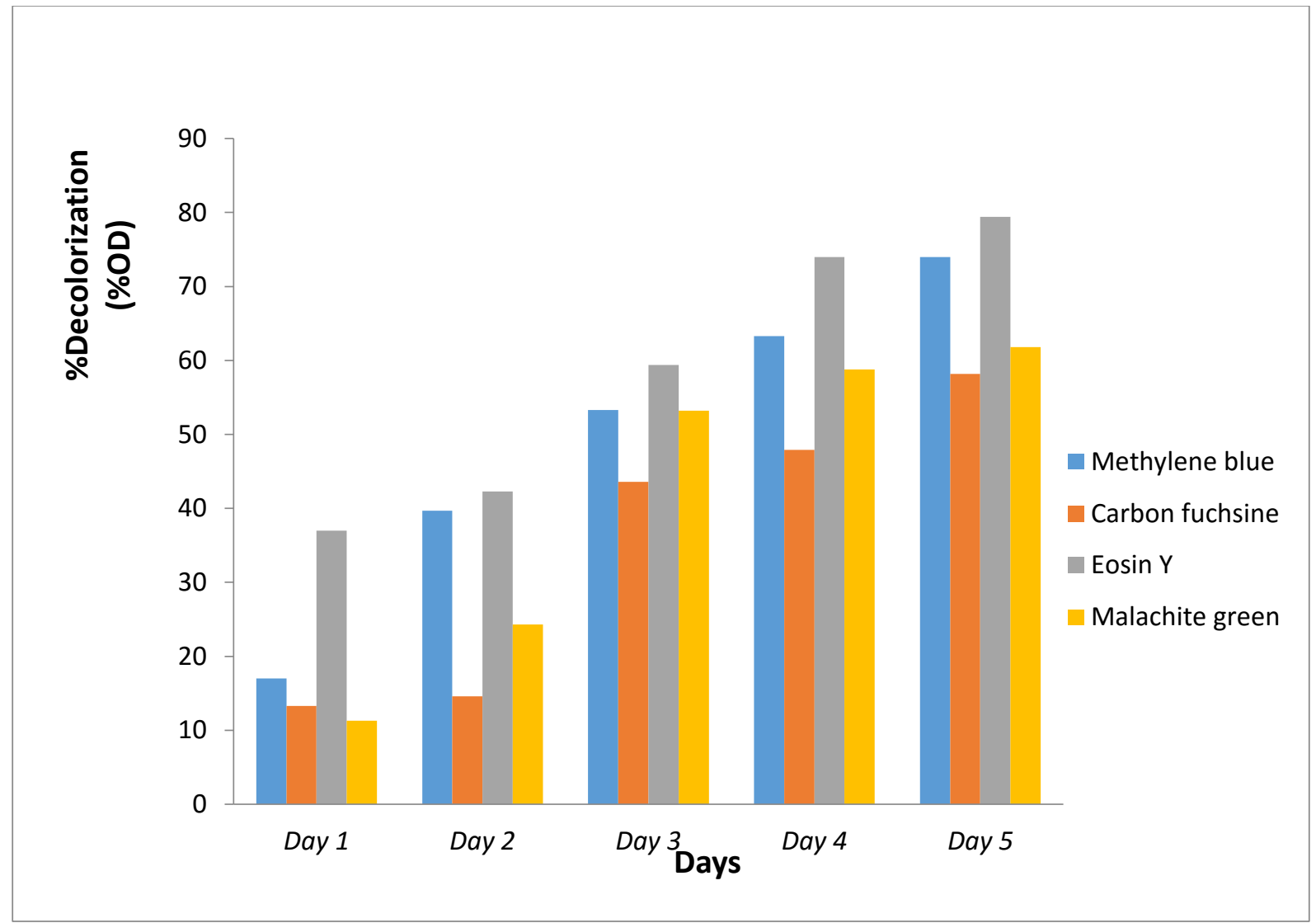

Fig. 2: Dyes Decolorization by A.Niger Inoculums from Day 1- 5. 


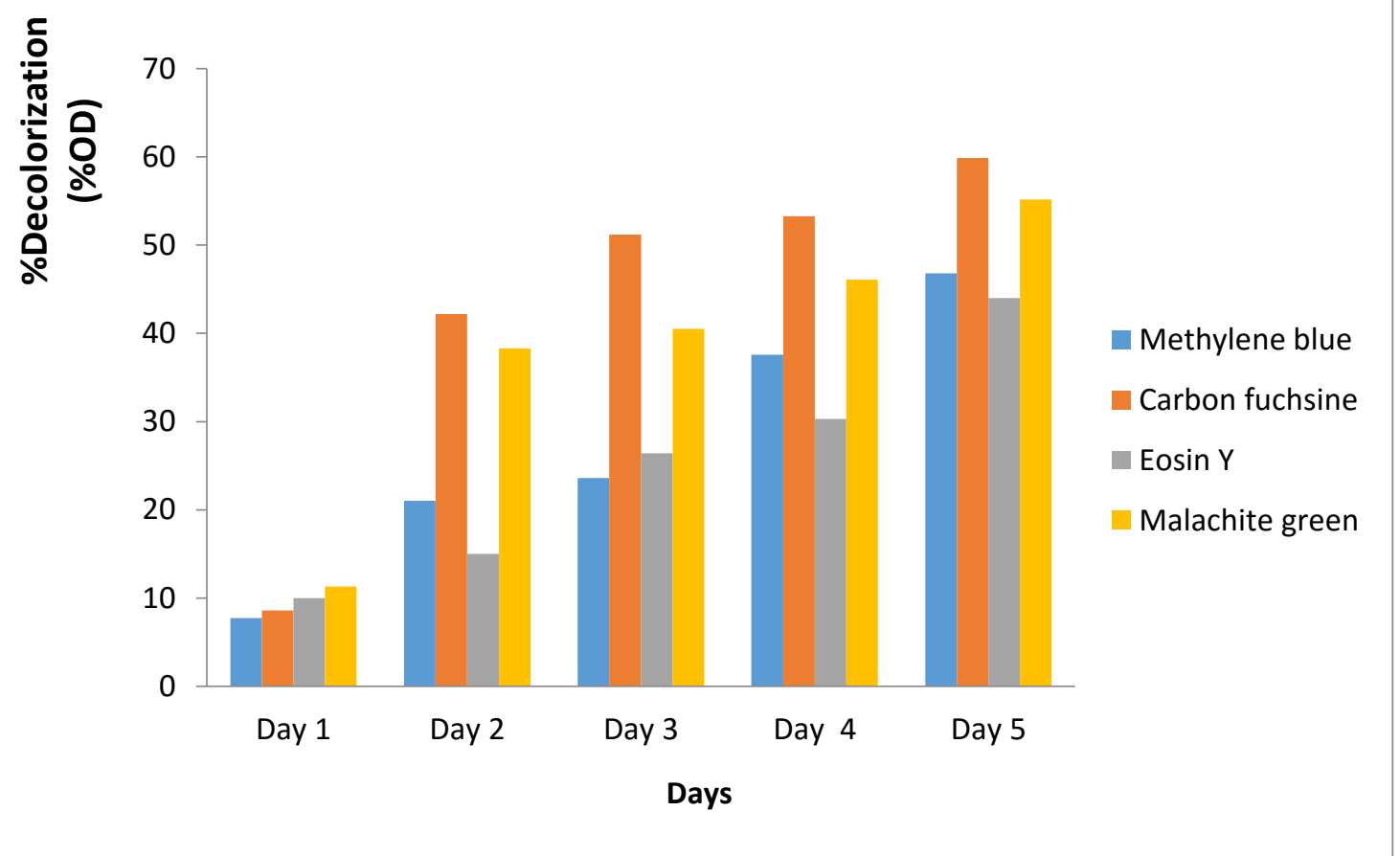

Fig. 3: Dyes Decolorization by A. Fumigatus Inoculums from Day 1-5.

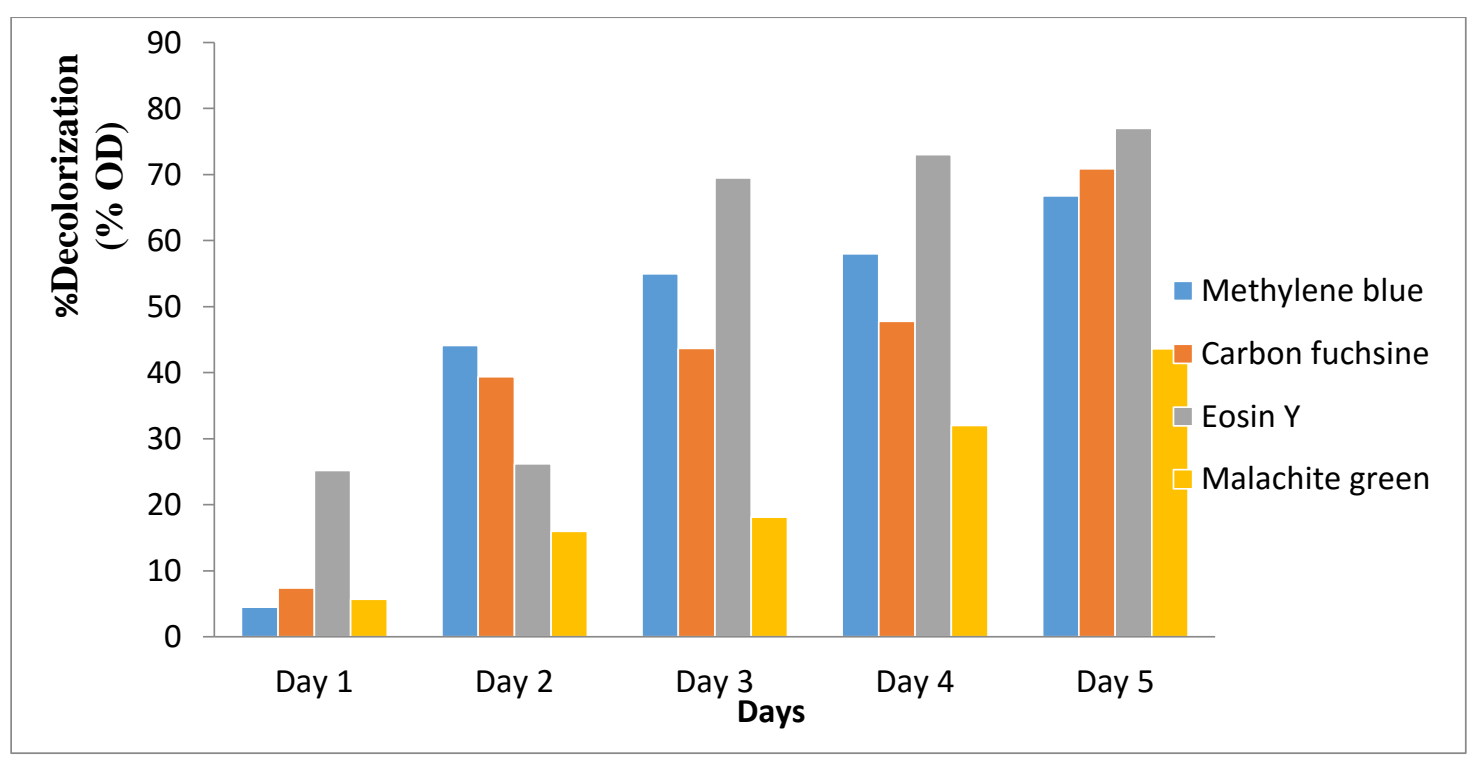

Fig. 4: Dyes Decolorization by Cryptococcus Spp. Inoculums from Day 1- 5. 


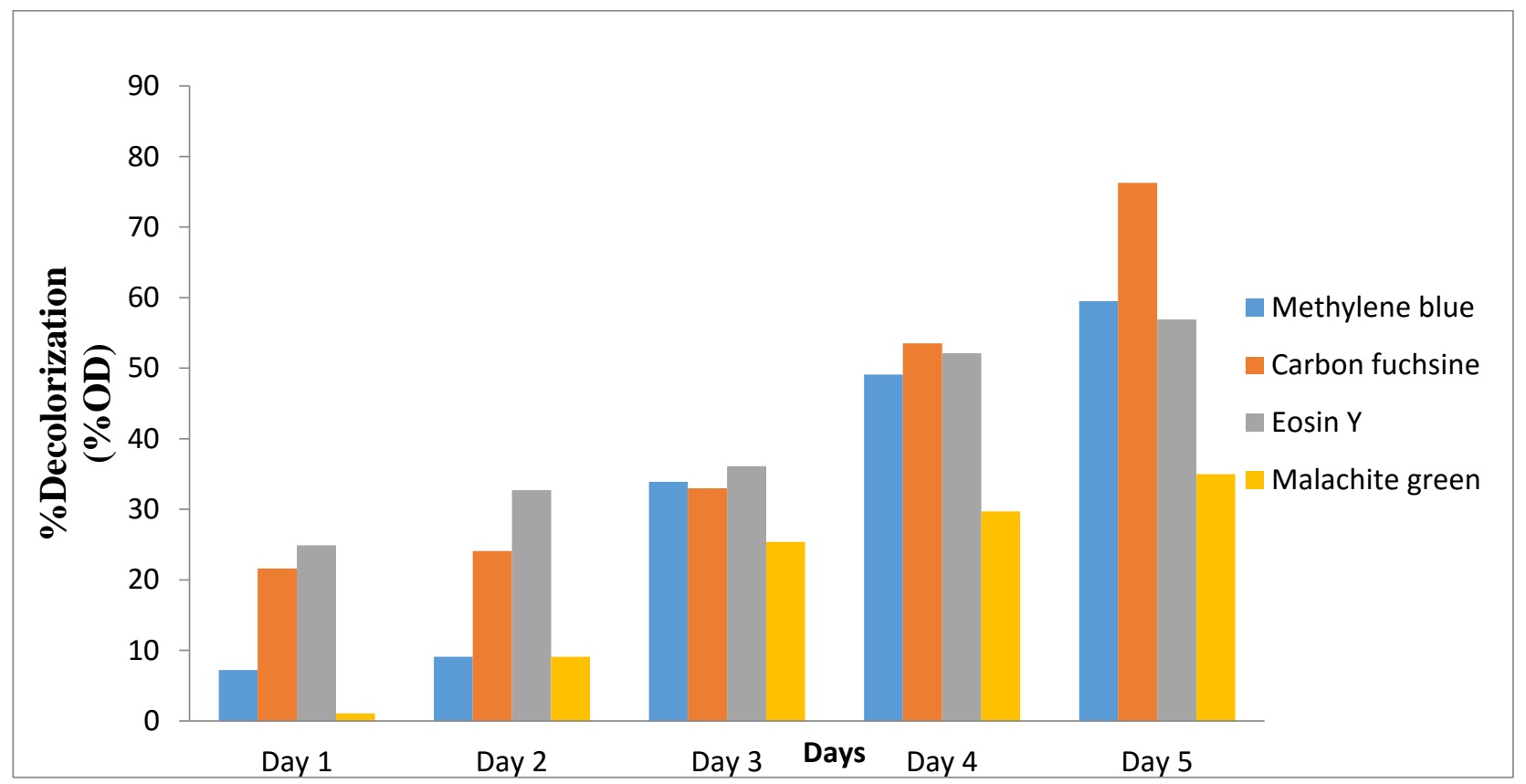

Fig. 5: Dyes Decolorization by Candida Albican Inoculums from Day 1-5.

\section{Discussion}

In the past years microbes have been drawing tremendous attention due to their ability to treat waste water and thereby improve water quality. Some microbes have the capability of coexistence with higher toxic level of contaminants such as dyes used in the textile industry which are highly recalcitrant to degradation. Consequently the identification and characterization of halotolerant and halophilic microbes that can degrade azo dyes may facilitate the development of biological method for treatment of saline azo dyes waste water (Ponraj et al., 2011).

Biological methods are environmentally safe and convert organic compounds completely into water and carbon dioxide; they are cost effective and easy to use (Ponraj et al., 2011). The result obtained in this research is in agreement with earlier reports from textile effluents study by Devi and Kaushik (2005), who reported that effluent of textiles can be treated with Aspergillus spp. Since they are well adapted to textile waste effluents and contaminated soils (Devi and Kaushik, 2005; Raju et al., 2007; Ponraj et al., 2011). The decolorization potential of the organisms most especially the white rot fungus Aspergillus niger has over the years been discovered to be due to their ability to produce extracellular ligninolytic enzymes which are observed by the oxidation of 3,4 dimethoxybenzyl alcohol to veratyldehyde in the presence of $\mathrm{H}_{2} \mathrm{O}_{2}$. Ligninase present in the extracellular extract of Aspergillus spp. were reported to exhibit properties comparable of other peroxidase with respect to their physiochemical properties (Jothimani and Prabakaran, 2003).

Moreover these lignin-degrading enzymes in Aspergillus spp. are directly involved not in the degradation of lignin in their natural ligninocellulose substrate but also in their degradation of various xenobiotics compounds, inclusive of dye (Wesenberg et al., 2003). Ligninolytic enzymes have been reported to oxidize many recalcitrant substances such as chlorophenols, polycyclic aromatic hydrocarbons (PAHs), organophosphorus compounds and phenols (Wesenberg et al., 2003). Our result support the idea that ligninolytic enzyme act on decolorizing the dye, it is possible that the ability of the fungi isolates to degrade dyes as shown in this study is coupled with their biosorption abilities in addition to their ability to produce extracellular enzymes (Park and Hausinger, 2007). Enzymes involved in the degradation of textile dyes are mainly peroxidases and laccases (Leena and Selva-Raj, 2008). In present study, laccase and peroxidase production by isolate was not de- tected in plate. Further investigation is needed to clarify the enzymatic mechanism responsible for dye biodegradation.

From the result, it was observed that carbon fuchsine dye was highly decolorizable by all fungal strains and the degradation efficiency varied from 58.2 to $76.3 \%$, exceeding the average percentage. Most of the isolated fungal species were able to decolorize eventually all selected dyes between 6-10 days (i.e. within 4 days), these decolorization efficiency of fungi can be due to the presence of chitin with hydroxyl and amino groups in their cell wall, which makes them an efficient absorbent of dye effluent (Park and Hausinger, 2007). Differences in the capacity of dye decolorization between fungi have been related to inter and intraspecific variations, the molecular complexity of the dye and the culture condition (Kirk et al., 1978).

\section{Conclusion}

The study has revealed that the fungal species examined are suitable candidates for decolorization and treatment of dye effluent and also seems to have a great significance for future development in removal and recovery of dyes. Biological systems appears to be the most economically viable choices available for effluent treatment/decolorization and the most practical in terms of manpower requirements and running expenses to adopt and develop.

\section{References}

[1] Ali, N., Hameed, A. and Ahmed, S. (2009). Physicochemical characterization and bioremediation perspective of textile effluent, dyes and metals by indigenous bacteria. J Hazard Mater 164: 322-328. http://dx.doi.org/10.1016/j.jhazmat.2008.08.006.

[2] Barnet, H. L., and Hunter, B. B. (1972). Illustrated General of Imperfect Fungi. Minneapolis Burgnees Publishing Company Minneapolis $M$. N. p241.

[3] Chen, B. Y., Chen, M. W., Wu, F. L., Chen, P. K., and Yen, C. Y. (2008). Revealing azo-dye decolorization of indigenous Aeromonas hydrophila from fountain spring in Northeast Taiwan. J. Chin. Insti. Chem. Eng. 39:495-501. http://dx.doi.org/10.1016/j.jcice.2008.05.004.

[4] Devi, M., and Kaushik, B. D. (2005). Decolorization of textile dyes and dye effluent by Aspergillus spp. Indian Journal of Microbiol. 45:41-44.

[5] Holt, J. G., Krieg, N., R., Sneath, P., H., Staley, J., T and Williams, S., T. (1994). Bergey's Manual of Determinative Bacteriology. MD Williams and Wilkins, Baltimore, Maryland. USA. 1-787.

[6] Jason, W. (2004). Bacteriology. NWFHS Laboratory Procedures Manual 2(5):1-15. 
[7] Joshi, T., Iyengar, L., Singh, K., and Gary, S. (2008). Isolation, identification and application of novel bacterial consortium TJ-1 for the decolorization of structurally different azo dyes. Bioresour. Technol.

99:7115-7121. http://dx.doi.org/10.1016/j.biortech.2007.12.074

[8] Jothimani, P. T. and Prabakaran, J. O. (2003). Dye factors effluent decolorization by fungal cultures under static condition. Journal of Ecological Biology 15:255-260.

[9] Kirk, T. K., Schultz, E., Connors, W. J., Lorenz, L.F., and Zeikus, J.G. (1978). Influence of culture parameters on lignin metabolism by Phanerochaete chrysosporium. Arch Microbiol, 117:277-285. http://dx.doi.org/10.1007/BF00738547.

[10] Leena, R. and Selva-Raj, D. (2008). Bio-decolorization of textile effluent containing Reactive Black B by effluent-adapted and nonadapted bacteria. Afr. J. Biotechnol. 7: 3309-3313.

[11] Mahbub, K. R., Ferdousi, J., and Anwar, M. N. (2001). Demonstration of decolorization of various dyes by some bacterial isolates recovered from textile effluents. Bangladesh J. Sci. Ind. Res. 46:323328.

[12] Mobely, H. L. T., Island, M. D., and Hausinger, R. P. (1995). Molecular biology of microbial urease. Microbial. Rev. 59: 451-479.

[13] Moorthi, S. P., Selran, P. S., Sasikalaveni, H. O., Murugesan, A. K. and Kalaichevan, P. T. (2007). Decolorization of dyes and their effluents using white rot fungi. African Journal of Biotechnology 6(4):424-429.

[14] Nosheen, S., Nawal, H., and Rehman, K. U. (2000). Physiochemical characterization of effluents of local textile industries Faisalabad Pakistan. Intern. J. of Agric. and Biol. 2(3):232-233.

[15] Ogawa, T., Idaka, E., and Horitsu H. (1982). Degradation pathway 15 of P-aminoazobenzene by Bacillus subtilis. Eur. J. Appl. Microbial. 141-143.

[16] Park, L.S., and Hausinger, R. P. (1995). Evidence for the presence urease apoprotein complexes containing UreD, UreF, and UreG in cells that are competent for in-vivo enzyme activation. J. Bacteriol. 177:1947-1951.

[17] Ponraj, M., Gokila, K., and Zambare, V. (2011). Bacterial Decolorization of Textile Dye- Orange 3R. Intern. Journal of Advances Biotechnology and Research 2(1):168-177.152.

[18] Raju, N. S., Venkataramana, G. V., Girish, S. T., Raghavendra, V. B. and Shivashankar, P. (2007). Isolation and evaluation of soil fungi for decolorization of textile dyes. Journal of Applied Science 7, 298-301. http://dx.doi.org/10.3923/jas.2007.298.301

[19] Selvam, K., Swaminathan, K. and Chae, K. S. (2003), Decolorization of azo dyes and a dye industry effluent by a white rot fungus Thelephora sp. Bioresource Technology 88, 115-119. http://dx.doi.org/10.1016/S0960-8524(02)00280-8.

[20] Thakur, M. C., Arif, K., and Hiren, D. (2012). Isolation and screening of dye degrading microorganism from the effluents of dye and textile industries at Surat. American Journal of Environ. Eng. 2(6):152-159. http://dx.doi.org/10.5923/j.ajee.20120206.02.

[21] Wesenberg, D., Kyriakides, I., and Agathos, S. N. (2003). White rot fungi and their enzymes for the treatment of industrial dye effluents. Biotechnology Advances 22:281-287. http://dx.doi.org/10.1016/j.biotechadv.2003.08.011.

[22] Zimmermann, T., Kulla, H. G., and Leisinger, T. (1982). Properties of purified orange 11 azoreductase, the enzyme initiating azo dye degradation by Pseudomonas KF46. Eur. J. Biochem. 129:197-203. http://dx.doi.org/10.1111/j.1432-1033.1982.tb07040.x.

[23] Zollinger, H. (1991). Colour Chemistry: syntheses, properties and application of organic dyes and pigments ( $2^{\text {nd }}$ edn), VCH Publication, New York, 496. 